\title{
Motor, sensory and functional recovery in patients with spinal cord lesions
}

\author{
L Müslümanoğlu ${ }^{1}, \mathrm{~S} \mathrm{Aki}{ }^{1}$, Y Öztürk ${ }^{2}, \mathrm{D} \mathrm{Soy}^{2}, \mathrm{M}$ Filiz $^{1}, \mathrm{~A}$ Karan ${ }^{1}$ and E Berker ${ }^{1}$ \\ ${ }^{1}$ Department of Physical Medicine and Rehabilitation, Istanbul Medical School Istanbul-Turkey; ${ }^{2} 70$. Yil Istanbul \\ Physical Medicine and Rehabilitation Center, Istanbul, Turkey
}

\begin{abstract}
The aim of this study is to evaluate the sensory, motor and functional improvement in patients with a Spinal Cord Lesion (SCL) by recording at admission, discharge and at 12 months after discharge. Fifty-five patients (29 with paraplegia and 26 with tetraplegia) admitted to our departments of Physical Medicine and Rehabilitation between December 1992-1995. Three patients were excluded as they did not give their consent. Each patient was evaluated at admission, before discharge and at 12 months after discharge. Motor status was evaluated by the motor score (MS), sensory status by the light touch score (LTS), and functional status by the Functional Independence Measure (FIM) score. Each patient was asked to complete a patient questionnaire which was developed according to the standards of the American Spinal Injury Association (ASIA) scale. Twelve patients (10 with paraplegia and two with tetraplegia) were evaluated at 12 months after discharge. Paired samples $t$-test was used for statistical analysis. The mean age of the patients group was $36.42+17.70$ years, the mean duration of inpatient rehabilitation was $93.87 \pm 44.95$ days. The SCL was due to trauma in 45 patients, $86.50 \%$ of the cases and was complete in nine patients $(17.30 \%)$ and incomplete in 19 $(36.53 \%)$ with paraplegia. Six tetraplegic patients $(11.53 \%)$ had complete and 18 had $(34.61 \%)$ incomplete lesions. The evaluation of MS, LTS and FIM scores at admission and discharge showed significant improvement in the MS and LTS in all of the patients with incomplete lesions $(P<0.001)$. FIM scores showed significant improvement only in those with complete or incomplete paraplegia $(P<0.05)$. At 12 months follow-up there was no significant change in the MS and the LTS whereas a significant change was noted in the FIM scores $(P<0.05)$ in 10 paraplegic patients. In summary, the results of this study indicate that rehabilitation was effective in our SCL series although the significant gain may also be attributed to the fact that $71.1 \%$ of the study group had incomplete neurological lesions.
\end{abstract}

Keywords: spinal cord injury; Functional Independence Measure, motor score, sensory score; neurological recovery

\section{Introduction}

In 1927 Harvey Cushing reported that $80 \%$ of spinal cord injured veterans died within several weeks after injury due to infection of the urinary tract and ischemic ulcers. Presently however $94 \%$ of these patients survive and lead functional useful lives owing to treatment in the rehabilitation and trauma centers. ${ }^{5,10,15}$ In the United States of America (USA) the reported prevalence of Spinal Cord Injury (SCI) is $200,000-250,000$ and the annual incidence is $24-50$ in a million. $5,18,28,29$ The incidence of SCI is lower than that of coronary disease and cancer but the financial burden of these patients in society is greater than both, and the treatment and rehabilitation needs are a socioeconomic challenge to society. ${ }^{18,25}$

The functional loss in SCI is due to neurological defects and immobilization and a period of $2-6$ weeks

Correspondence: L Müslümanoğlu of strict bed rest results in deterioration of the musculoskeletal and cardiovascular systems. ${ }^{4}$ The basic aim of rehabilitation in SCI is to minimize the negative effects of immobilization, and to prevent complications. ${ }^{4,12,14}$ Sudden disability resulting from SCI affects family members and their quality of life as well. ${ }^{21}$ Rehabilitation procedures aim to teach the patient independence in the activities of daily living, ambulation, and social integration depending on the degree of severity of the neurological defects.

In this study our aim was to evaluate the effectiveness of rehabilitation in our SCL patients by recording MS, LTS and FIM score at admission, discharge and at 12 months after discharge.

\section{Materials and methods}

Fifty-five SCL patients (29 paraplegic and 26 tetraplegic) were admitted to our departments of Physical 
Medicine and Rehabilitation during 1992-1995 for inpatient rehabilitation. Fifty-two gave their consent and were recruited for the study. Nine patients had complete and 19 incomplete paraplegia. Six tetraplegic patients had complete and 18 incomplete neurological lesions. All patients were evaluated on the first day of admission, at discharge and 10 with paraplegia were evaluated at 12 months follow-up by MS, $\operatorname{LTS}^{1,6,12,19}$ and FIM recordings. ${ }^{1,8,11,20,23}$ A patients' questionnaire developed in accordance with ASIA standards was completed by each patient and the degree of the lesion was determined by the same scale. ${ }^{1,6}$ Although each patient was recalled for reevaluation at 12 months, only 10 patients with paraplegia and two with tetraplegia attended for reevaluation. Paired samples $t$-test was used for statistical analysis.

\section{Results}

The mean age of the patients group was $36.42 \pm 17.70$ years and the mean duration of inpatient rehabilitation was $93.87 \pm 44.95$ days. The educational level of the group was low, uneducated and primary school graduated being $67.3 \%$ of the total cases (Table 1). SCL was due to trauma in 21 people with paraplegia and 21 with tetraplegia $(80.7 \%)$, tumor in four patients (three paraplegic and one tetraplegic) $(7.7 \%)$, infection in three patients (two paraplegic and one tetraplegic) $(5.8 \%)$ and degenerative lesions in three patients (two paraplegic and one tetraplegic) $(5.8 \%)$. Falls, traffic accidents and head-on diving were the three main causes of traumatic SCL in this series. (Table 2). Nine with paraplegia $(17.30 \%)$ had incomplete, and 19 paraplegic patients $(36.53 \%)$ had complete lesions. Six with tetraplegia $(11.53 \%)$ had complete, 18 $(34.61 \%)$ had incomplete lesions. The evaluation of

Table 1 Demographic features of the subjects

\begin{tabular}{lcc}
\hline & Number & $\%$ \\
\hline Gender & & \\
$\quad$ Female & 20 & 38.5 \\
$\quad$ Male & 32 & 61.5 \\
Education & & \\
$\quad$ No education & 13 & 25 \\
Primary school & 22 & 42.3 \\
High School & 12 & 23 \\
$\quad$ College & 5 & 9.6 \\
Marital status & 32 & 61.5 \\
$\quad$ Married & 15 & 28.8 \\
Single & 5 & 9.6 \\
$\quad$ Widow & \multicolumn{2}{c}{28.9} \\
ASIA impairment scale & 15 & 71.1 \\
$\quad$ Complete & 37 & \multicolumn{2}{c}{ Medium \pm SD } \\
Incomplete & \multicolumn{2}{c}{$36.42 \pm 17.70$} \\
& \multicolumn{2}{c}{$93.87 \pm 44.95$} \\
\hline Age (5-75 years) & \multicolumn{2}{c}{} \\
Duration of rehabilitation & (14-258 days) &
\end{tabular}

MS, LTS and FIM score at admission and discharge showed significant improvement in MS and LTS in all patients with incomplete lesions $(P<0.001)$ whereas FIM scores were significant only in those with paraplegia with complete or incomplete lesions $(P<0.05)$ (Table 3$)$. The reevaluation of 10 paraplegic patients at 12 months follow-up showed no significant difference in MS and LTS scores whereas significant progress was noted in FIM scores $(P<0.05)$. (Table 4$)$. The results of follow-up evaluation of those with tetraplegia are not included in the study since only two such patients attended.

\section{Discussion}

Several studies have reported that the mean age of spinal cord injured (SCI) patients is in the third decade. ${ }^{2,3,5,12,17,22,27}$ Some other studies however report a range from the second to fourth decades. $^{9,15,16,26,29-31}$ In our study the mean age of the group was on the third decade. SCI is more common in the male $\operatorname{sex}^{2,7,9,17}$ and epidemiological studies report a percentage of $80 \% \cdot{ }^{3,5,29,30}$ In our study the male/female ratio was $32 / 20$.

The mean duration of inpatient rehabilitation was $93.87 \pm 44.95$ days in our study. De Vivo et al. have shown this duration to be 97.9 days during 1973-1977 and this period shortened to 76.6 days in 1986-1987. Several studies from our country have shown the mean inpatient rehabilitation duration to be $54.4,{ }^{22} 55.9^{31}$ and 139 days. $^{2}$ Studies from USA show that the hospital stay for tetraplegic patients was 149 days in $1974^{5}$ and has been shortened to 92 days in 1989 .

The most common etiological factor in SCI is trauma. $2,3,5,7,9,14,16-18,22$ In our study a traumatic etiology was noted in $80.7 \%$ of the cases. Traumatic factors were falls from high places in $36.5 \%$, traffic accidents in $19.2 \%$, diving in $9.6 \%$.

In the USA the most common factors responsible for SCI are motor vehicle accidents in $45 \%$, falls in $22 \%$, fights in $16 \%$ and sports accidents in $13 \% .^{3,5}$ In our study there was a low educational level. Living in surburban areas which may account for the fact that falls have a higher percentage than motor vehicle accidents among the etiological factors for SCI.

Table 2 Etiological factors in patients witha a Spinal Cord Lesion

\begin{tabular}{lcc}
\hline & Number & $\%$ \\
\hline Trauma & 42 & 80.7 \\
Falls & 19 & 36.5 \\
Traffic accidents & 10 & 19.2 \\
Diving & 5 & 9.6 \\
Iatrogenic & 4 & 7.6 \\
Gunshot wounds & 4 & 7.6 \\
Tumor & 4 & 7.7 \\
Degenerative & 3 & 5.8 \\
Infection & 3 & 5.8 \\
\hline
\end{tabular}


Table 3 Motor, sensory and functional recovery at admission and on discharge

\begin{tabular}{|c|c|c|c|}
\hline & Number & $M e d i u m \pm S D$ & $\mathrm{P}$ \\
\hline $\begin{array}{l}\text { *M.S.A.-M.S.D. } \\
\text { Paraplegia incomplete admission } \\
\text { Paraplegia incomplete discharge } \\
\text { Paraplegia complete admission } \\
\text { Paraplegia complete discharge } \\
\text { Tetraplegia incomplete admission } \\
\text { Tetraplegia incomplete discharge } \\
\text { Tetraplegia complete admission } \\
\text { Tetraplegia complete discharge }\end{array}$ & $\begin{array}{r}19 \\
19 \\
9 \\
9 \\
18 \\
18 \\
6 \\
6\end{array}$ & $\begin{array}{l}63.22 \pm 19.28 \\
71.93 \pm 17 / 88 \\
50.33 \pm 1.87 \\
52.00 \pm 3.77 \\
40.22 \pm 24.27 \\
57.05 \pm 26.47 \\
11.50 \pm 10.50 \\
20.66 \pm 11.97\end{array}$ & $\begin{array}{c}P<0.001 \\
* * \text { N.S. } \\
P<0.001 \\
\text { N.S. }\end{array}$ \\
\hline $\begin{array}{l}\text { L.T.S.A-L.T.S.D. } \\
\text { Paraplegia incomplete admission } \\
\text { Paraplegia incomplete discharge } \\
\text { Paraplegia complete admission } \\
\text { Paraplegia complete discharge } \\
\text { Tetraplegia incomplete admission } \\
\text { Tetraplegia incomplete discharge } \\
\text { Tetraplegia complete admission } \\
\text { Tetraplegia complete discharge }\end{array}$ & $\begin{array}{r}19 \\
19 \\
9 \\
9 \\
18 \\
18 \\
6 \\
6\end{array}$ & $\begin{array}{c}98.10 \pm 15.62 \\
101.26 \pm 14.14 \\
66.33 \pm 15.18 \\
68.33 \pm 12.28 \\
83.22 \pm 31.68 \\
90.61 \pm 28.34 \\
25.66 \pm 12.80 \\
36.50 \pm 9.79\end{array}$ & $\begin{array}{c}P<0.001 \\
\text { N.S. } \\
P<0.001 \\
\text { N.S. }\end{array}$ \\
\hline $\begin{array}{l}\text { F.I.M.A.-F.I.M.D. } \\
\text { Paraplegia incomplete admission } \\
\text { Paraplegia incomplete discharge } \\
\text { Paraplegia complete admission } \\
\text { Paraplegia complete discharge } \\
\text { Tetraplegia incomplete admission } \\
\text { Tetraplegia incomplete discharge } \\
\text { Tetraplegia complete admission } \\
\text { Tetraplegia complete discharge }\end{array}$ & $\begin{array}{r}19 \\
19 \\
9 \\
9 \\
18 \\
18 \\
6 \\
6\end{array}$ & $\begin{array}{l}72.50 \pm 20.84 \\
97.00 \pm 19.58 \\
61.00 \pm 12.18 \\
74.44 \pm 17.72 \\
51.00 \pm 15.26 \\
79.94 \pm 27.47 \\
49.83 \pm 9.43 \\
59.50 \pm 14.36\end{array}$ & $\begin{array}{c}P<0.05 \\
P<0.05 \\
P<0.05 \\
\text { NS }\end{array}$ \\
\hline
\end{tabular}

*M.S.A.-D.: Motor Score Admission-Discharge; L.T.S.A.-D.: Slight Touch Score Admission-Discharge; F.I.M.A.-D.: Functional Independence Measure Admission-Discharge; **N.S.: Not Significant

Table 4 Motor, sensory and functional recovery at discharge and 12 months after discharge

\begin{tabular}{|c|c|c|c|}
\hline & Number & $M e d i u m \pm S D$ & $\mathrm{P}$ \\
\hline \multicolumn{4}{|l|}{ Motor Score } \\
\hline Paraplegia discharge & 10 & $71.71 \pm 16.83$ & *N.S. \\
\hline $\begin{array}{l}\text { Paraplegia } 12 \text { months } \\
\text { after discharge }\end{array}$ & 10 & $72.14 \pm 15.62$ & \\
\hline \multicolumn{4}{|l|}{ Light Touch Score } \\
\hline Paraplegia discharge & 10 & $88.28 \pm 24.77$ & N.S. \\
\hline $\begin{array}{l}\text { Paraplegia } 12 \text { months } \\
\text { after discharge }\end{array}$ & 10 & $91.57 \pm 25.74$ & \\
\hline \multicolumn{4}{|c|}{ Functional Independence Measure } \\
\hline Paraplegia discharge & 10 & $94.80 \pm 15.95$ & $P<0.05$ \\
\hline $\begin{array}{l}\text { Paraplegia } 12 \text { months } \\
\text { after discharge }\end{array}$ & 10 & $103.90 \pm 90$ & \\
\hline
\end{tabular}

*N.S.: Not Significant

The results of the epidemiological study by Murray et $a l^{14}$ indicate that trauma is the most common etiological factor in those below 40 years of age $(69 \%)$. In those over 40 , neoplasms $(53 \%)$, spondylosis $(25 \%)$ and trauma $(13 \%)$ are the responsible factors.

Since $71.1 \%$ of patients in our series had incomplete lesions, our patients had the chance of spontaneous neural recovery which may be reflected by the significant change from admission and discharge. There was a significant progress in MS, LTS and FIM scores in all incomplete cases, independent of the level of lesion (MS and LTS $P<0.001$, FIM $P<0.05$ ) in our study. No significant change in MS, LTS and FIM scores were noted $(P<0.05)$ in incomplete lesions. Although no significant difference was noted in MS and LTS scores in cases with complete lesions, significant progress noted in FIM scores at discharge and 12 months follow-up may account for the effectiveness of rehabilitation and former studies on this subject also support this point. ${ }^{32-34}$

This significant improvement in FIM scores both at discharge and at 12 months follow-up points to the effectiveness of rehabilitation and emphasizes the need for objective evaluation and recording criteria for the long-term follow-up of SCI patients.

\section{References}

1 American Spinal Injury Association: Standards for neurological and functional classification of spinal injury, Revised 1992 Paraplegia 1994; 32: (2) 70-80.

2 Balci N, Beyazova M: Medulla spinalis lezyonlu hastalarin degerlendirilmesinde veri tabani kullanimi. Fizik Ted Rehabil Derg 1994; 18(2): $103-107$. 
3 De Vivo MJ et al. Trends in spinal cord injury demographics and treatment outcomes between 1973-1986. Arch Phys Med Rehabil 1992; 73: $424-430$.

4 Decker M, Hall A. Physical therapy in spinal cord injury. In: Blocch RF, Basbaum M (eds). Management of spinal cord injuries. Baltimore, Williams \& Wilkins. 1986; 320-347.

5 Ditunno JF, Formal CS. Chronic spinal cord injury. $N$ Engl J Med. 1994; 330(8): $550-556$.

6 Ditomno JF, Young W, Donovan WH, Creaasey G. The international standards booklet for neurological and functional classification of spinal cord injury. Paraplegia 1994; 32: 70-80.

7 Dixon GS, Danesh JN, Caradoc-Davies TH. Epidemiology of spinal cord injury in New Zealand. Neuroepidemiolgy (abst). 1993; 12(2): $88-95$.

8 Grey N, Kennedy P. The functional independence measure: A comparative study of clinician and self ratings. Paraplegia 1993; 31: $457-461$.

9 Gündüz S, et al. Omurilik yaralanmali hastalarda ürolojik sonuclar. Fizik Ted Rehabil Derg 1991; 15(19): 9-4.

10 Gündüz S, Möhür H, Civitci B, Yazicioglu K. Spinal kord yarali hasta merkezleri ve uzmanligi. Fizik Ted Rehabil Derg 1993; 17(1): $31-33$

11 Johnston MV, Keith RA, Hinderer SR: Measurement standards for interdisciplinary rehabilitation. Arch Phys Med Rehabil (supplement) 1992; 73: 3-23.

12 Lazar RB, Yarkony GM, Ortolano D, et al. Prediction of functional outcome by motor capability - after spinal cord injury. Arch Phys Med Rehabil 1989; 70: 819-822.

13 Mange KC, Ditunno JF, Herbison GJ, Javeed MM. Recovery of strength at the zone of injury in motor complete and motor incomplete cervical spinal cord injured patients. Arch Phys Med Rehabil 1990; 71: $562-565$.

14 Murray PK, Kusior MF. Epidemiology of nontraumatic spinal cord injury. Arch Phys Med Rehabil 1984; 65: 634.

15 Oakes DD, Wilmot CB, Hall KM, Sherck JP. Benefits of early admission to a comprehensive trauma center for patients with spinal cord injury. Arch Phys Med Rehabil 1990; 71: 637-643.

16 Özcan E, Toklu M, Sengir O, Yücel K: 1983-1988 yillari arasinda klinigimizde yatirilarak rehabilite edilen 25 paraplejik hastanin özellikleri. Fizik Ted Rehabil Derg 1989; 81(2): 10-11.

17 Özcan O, Kahraman Z, Aytekin H, Pekanik N. Travmatik omurilik yaralanmali hastalarin epidemiyolojik analizi. Fizik Ted Rehabil Derg 1993; 17(4): 187 - 189.

18 Price C, Makintubee S, Hendon W, Istre GR. Epidemiology of traumatic spinal cord injury and acute hospitalization and rehabilitation charges for spinal cord injuries in Oklahoma, 1988-1994: Am J Epidemiol 139(1): 37 - 47.

19 Prieme MM, Waring WP: The interobserver reliability of the revised American Spinal Association standards for neurological classification of spinal injury patients. Am J Phys Med Rehabil 1991; 70(5): $268-270$.
20 Procedures for scoring the functional independence measure (FIM). Research Foundation of the State University of New York, 1990.

21 Richards JS. Psychologic adjustmenmt to spinal cord injury during first postdistcharge year. Arch Phys Med Rehabil 1986; 67: $362-365$.

22 Sayiner N, Abenyakar S, Durlanik G, Boneval F: Spinal kord yaralanmali hastalarimizin özellikleri ve günlük yasam aktivitelerinin degerlendirilmesi. Fizik Ted Rehabil Derg 1992; XVI(3): $131-134$.

23 Segal ME, Ditunno JF, Staas WE. Interinstitutional agreement of individual functional independence measure (FIM) items measured at two sites on one sample of SCI patients. Paraplegia 1993; 31: $622-631$.

24 Staas WE, Formal CS, Gershkoff AM, et al. Rehabilitation of the spinal cord injured patient In: De Lisa JA (ed). Rehabilitation Medicine Philadelphia, J:B. Lippincott 1988; 635-659.

25 Tate DG, Forchheimer M, Daugherty J, Maynard F. Determining differences in post discharge outcomes among catastrophically and noncatastrophically sponsored outpatients with spinal cord injury. Am J Phys Med Rehabil 1994; 73(2): 89-97.

26 Waters RL, Adkins RH, Yakura JS, Sie I. Motor and sensory recovery following incomplete paraplegia. Arch Phys Med Rehabil 1994; 75: $67-72$

27 Waters RL, Adkins RH, Yakura JS, Sie I. Motor and sensory recovery following incomplete tetraplegia. Arch Phys Med Rehabil 1994; 75: 306-311

28 Welch RD, Lobley SJ, O'Sullivan SB, Freed MM. Functional Independence in Quadriplegia: Critical Levels. Arch Phys Med Rehabil 1986; 67: 235-240.

29 Woodruff BA, Baron RC. A description of nonfatal spinal cord injury using a hospital-based registry. Am J Prev Med (abst) 1994; 10(1): $10-14$

30 Yarkony GM et al. Functional skills after spinal cord injury rehabilitation: Three-years longitudinal follow-up. Arch Phys Med Rehabil 1988; 69: $111-114$.

31 Yarkony GM et al. Benefits of rehabilitation for traumatic spinal cord injury. Multivariate analysis in 711 patients. Arch Neurol 1987; 44: $93-96$.

32 Young JS, Burns PE, Bowen AM et al. Spinal Cord Injury Statistics: Experience of the Regional Spinal Cord Injury Systems. Phoenix, Good Samaritan Medical Center, 1982.

33 Woolsey RM. Rehabilitation outcome following spinal cord injury. Arch Neurol 1985; 42: 116-119.

34 Nixon V. Spinal Cord Injury: A Guide to Functional Outcomes in Physical Therapy Management. Rockville, Md, Aspen Systems Corp, 1985 